\title{
Comparison and testing the reliability of two non-radiographic techniques of mixed dentition space analysis in Nepalese population
}

\author{
Rajeev Kumar Mishra, Vasant Devagiri \\ Department of Orthodontics, College of Medical sciences, Bharatpur, Nepal
}

\section{Correspondence}

Dr Rajeev Kumar Mishra, Department of Orthodontics, College of Medical sciences, Bharatpur, Nepal

\section{Email:}

mishra.rkm84@gmail.com

DOI: http://dx.doi.org/10.3126/ jemsn.v13i4.18617

Orcid ID: orcid.org/0000-0002 $-6933-3618$

Article received: Nov $16^{\text {th }} 2017$ Article accepted: Dec $10^{\text {th }} 2017$

\begin{abstract}
Background \& Objectives: Mesio-distal tooth size-arch length discrepancy is one of the major sources of malocclusion. Accurate prediction of space required for unerupted tooth can help in early interception of developing malocclusion. Various methods have been proposed for prediction of mesio-distal tooth size however accuracy of such methods in population groups other than that on which these methods are based remains questionable. The aims and objectives of this study were to test the reliability of Moyer's and Tanaka-Johnston mixed dentition analysis in Nepalese population, to construct prediction tables for Nepalese population if these methods were found not reliable. Materials \& Methods: Study models of 77 subjects (31 males,46 females) fulfilling the inclusion criteria were retrieved from department archive. Tooth dimensions were measured using electronic digital caliper. Moyer's and Tanaka-Jhonston methods were applied to predict the mesio- distal tooth size of canines and premolars. The predicted values were compared with the actual mesio-distal tooth size. A regression equation based on actual canine and premolar mesio-distal dimensions and sum of mandibular permanent incisors was also developed. Results: Independent t-test showed that there was no significant difference between mesio-distal tooth size in males and females. Paired t-test showed that there was no difference in mesio-distal tooth size between right and left sides of the arch. Tanaka - Johnston analysis overestimated the mesio-distal size in both males and females. Moyer's method at $75 \%$ overestimated the mesio-distal size in male and female and the difference was statistically significant while at $50 \%$ it underestimated the tooth size in females. Conclusion: Moyer's and Tanaka-Jhonston method of mesio-distal size prediction are inaccurate when applied in Nepalese population. A new regression equation to predict the size of tooth has been presented.
\end{abstract}

Key words: Mixed dentition; Nepalese population; Moyer's method; Tanaka-Jhonston method

Citation: Mishra RK, Devagiri V. Comparison and testing the reliability of two non-radiographic techniques of mixed dentition space analysis in Nepalese population. JCMS Nepal. 2017;13(4):410-5.

\section{INTRODUCTION}

Tooth -size arch length discrepancy is one of the common contributing factor in developing malocclusion. ${ }^{1}$ Accurate prediction of unerupted permanent mesio-distal size may help in early interception of malocclusions arising due to tooth size arch length discrepancy. Various methods have been proposed for such purpose which use either dental cast or radiograph or both.
Moyer's mixed dentition analysis ${ }^{2}$ and TanakaJhonston mixed dentition analysis ${ }^{3}$ are one of the most commonly used methods to predict the size of unerupted permanent teeth (canines and premolars). These methods are easy to use and provide reasonably accurate prediction of size of unerupted canines and premolars for North European population groups on which the data is based but the accuracy of these methods for other population 
groups remains questionable. ${ }^{4-7}$ Results of previous studies done in Nepalese population show that both these methods have questionable accuracy when applied to Nepalese population groups. ${ }^{8,9}$ The aims and objectives of this study were to test the reliability of Moyer's and Tanaka Johnston mixed dentition analysis in Nepalese population, to construct prediction tables for Nepalese population if these methods were found not reliable.

\section{MATERIALS AND METHODS}

Study models of 77 subjects ( 31 males, 46 females) were retrieved from department archives. Inclusion criteria for this study were: subjects with Nepalese ancestry, presence of teeth at least up to permanent second molar. Subjects with large inter-proximal restorations, clinically apparent abnormal mesiodistal size, previous history of orthodontic treatment were excluded. The mesio-distal width of mandibular incisors and canines and premolars in all quadrants were measured with electronic digital caliper (range: $0-150 \mathrm{~mm}$,accuracy: $\pm 0.02 \mathrm{~mm}$ ). The measurements were made perpendicular to the long axis of tooth by entering the caliper beak form interproximal area or occlusal side. All measurements were made by single investigator (RKM). Teeth were measured to nearest $0.1 \mathrm{~mm}$. The sum of four mandibular incisors was used to predict the mesio-distal size of canines and premolars. Measurements were repeated in 20 cases after one week interval to check reliability of measurement. Sum of mesio-distal size of canines and premolars predicted by Moyer's and TanakaJhonston method were compared with actual mesio -distal size of canines and premolars measured from dental cast.

\section{RESULTS}

Mean age for males was $21.1 \pm 3.7$ and for females it was $21.3 \pm 5.7$ years. Kolmogrov -smirnov test showed that data distribution was normal. Intra class correlation coefficient was higher than 0.9 indicating high intra-observer reliability of measurements. Independent t-test showed that there was no significant difference between sum of mesio-distal tooth size of males and females (Table 1). Paired t-test showed no significant difference between sum of mesio-distal width of canines and premolars in right and left side of arches (Table 2), hence for further analysis mean of left and right sides was used. Paired t-test was used to test the difference between predicted mesio-distal size values and measured mesio-distal size values. Moyer's analysis at $75 \%$ overestimated the mesiodistal size in maxillary and mandibular arches for both males and females. The difference was statistically significant. In males, Moyer's analysis at $50 \%$ overestimated the mesio-distal size but the difference was not statistically significant. In females, Moyer's analysis at 50\% underestimated the mesio-distal size and the difference was statistically significant. Tanaka-Jhonston analysis also overestimated mesio-distal size in maxillary and mandibular arches for both males and females. These differences were also statistically significant. (Table 3)

A prediction equation based on sum of mandibular incisors and actual mesio-distal width of canines and premolars was developed. The characteristics of obtained regression equation is depicted in Table 4. Pearson correlation coefficient ( $r$ ) for maxillary arch was 0.75 and for mandibular arch was 0.76.Standard error of mean ranged from 0.87 to 1.0. The developed prediction equations for males and females are depicted in Table 5. Using these prediction equation, mesio-distal size prediction table was developed for Nepalese males $\&$ females (Table 6).

\section{DISCUSSION}

High correlation has been reported between size mandibular permanent incisor and sum of size of canines and premolar. ${ }^{2}$ Hence this method is frequently used to predict the size of unerupted canines and premolars in space management procedures. Regression methods developed by Moyer's and Tanaka-Jhonston are most commonly used methods because it requires no special equipment or radiographs, are easy to carry out and has low systematic errors. ${ }^{2}$ The aim of our study was to check the reliability of Moyer's and Tanaka -Jhonston methods when applied to Nepalese population.

As previously reported by Gyawali et $\mathrm{al}^{8}$, for power $=0.8$ and significance level 0.05 , sample size of $\approx 90$ is required .In our study, we measured the mesio-distal tooth size of seventy seven subjects and difference between predicted and actual mesiodistal tooth size was analyzed. In our study crowding was not used as exclusion criteria. The relationship between crowding and mesio-distal tooth size is not clear. Some studies report that crowded dentition have larger mesio-distal tooth size ${ }^{10,11}$ while other studies have reported no 
Table 1: Comparision of tooth size between males \& femlaes

\begin{tabular}{|c|c|c|c|c|}
\hline & Sex & Mean \pm S.D. & Range & p-value \\
\hline \multirow{2}{*}{$\sum$ Mandibular incisors } & M & $22.4 \pm 1.6$ & $19.2-26.1$ & \multirow{2}{*}{0.90} \\
\hline & $\mathrm{F}$ & $22.5 \pm 1.6$ & $18.8-25.9$ & \\
\hline \multirow{2}{*}{$\sum$ Maxillary CPM } & M & $20.9 \pm 1.5$ & $18.2-24.9$ & \multirow{2}{*}{0.64} \\
\hline & $\mathrm{F}$ & $20.8 \pm 1.2$ & $17.0-23.6$ & \\
\hline \multirow{2}{*}{$\sum$ Mandibular CPM } & M & $20.8 \pm 1.6$ & $20.8-24.9$ & \multirow{2}{*}{0.48} \\
\hline & $\mathrm{F}$ & $20.6 \pm 1.4$ & $17-23.6$ & \\
\hline
\end{tabular}

$\sum \mathrm{CPM}$; Combined width of canine and premolars

Table-2: Comparison of width of canines \& premolars between right and left side

\begin{tabular}{llll} 
& Right side & Left side & p-value \\
\hline CCPM (Maxilla) & $20.9 \pm 1.4$ & $20.8 \pm 1.4$ & 0.11 \\
\hline CCPM (Mandible) & $20.4 \pm 1.4$ & $20.3 \pm 1.3$ & 0.24
\end{tabular}

$\Sigma \mathrm{CPM}$; Combined width of canine and premolars

Table 3: Comparison of actual tooth size and tooth size predicted by Moyer's and Tanak-Johnston Meth-

\begin{tabular}{|c|c|c|c|c|c|}
\hline Arch & Prediction method & $\begin{array}{c}\text { Mean difference (Actual - } \\
\text { predicted) }\end{array}$ & SD & SEM & Sig \\
\hline \multirow{3}{*}{ Maxilla (male) } & Moyers 75\% & -0.78 & 1.0 & 0.17 & $0.00 *$ \\
\hline & Moyers 50\% & -0.19 & 1.0 & 0.19 & 0.32 \\
\hline & Tanaka-Johnston & -1.2 & 1.0 & 0.18 & $0.00 *$ \\
\hline \multirow{3}{*}{ Mandible(male) } & Moyers 75\% & -0.8 & 1.1 & 0.2 & $0.00^{*}$ \\
\hline & Moyers 50\% & -0.01 & 1.1 & 0.2 & 0.93 \\
\hline & Tanaka-Johnston & -0.87 & 1.1 & 0.2 & $0.00^{*}$ \\
\hline \multirow{3}{*}{ Maxilla(female) } & Moyers 75\% & -0.42 & 1.0 & 0.14 & $0.00 *$ \\
\hline & Moyers 50\% & 0.33 & 1.0 & 0.15 & $0.03 *$ \\
\hline & Tanaka-Johnston & -1.4 & 0.86 & 0.12 & $0.00 *$ \\
\hline \multirow{3}{*}{ Mandible(Female) } & Moyers 75\% & -0.5 & 0.96 & 0.14 & $0.01 *$ \\
\hline & Moyers 50\% & 0.31 & 0.96 & 0.14 & $0.03 *$ \\
\hline & Tanaka-Johnston & -1.1 & 1.1 & 0.14 & $0.00 *$ \\
\hline
\end{tabular}

significant difference between mesio-distal tooth size in crowded and non-crowded group. ${ }^{12}$ Since our study sample was based on records of subjects reporting to OPD for orthodontic correction, crowding as exclusion criteria would have resulted in very small sample size. No significant difference was found between combined mesio-distal tooth size of males and females which is in contrast to previous studies done in Nepalese samples. This may be due to variation in sample selection.

On examination of mesio-distal tooth size difference between left and right side, no significant difference was found. The genetic fields within which permanent mesio-distal size is controlled extend to involve a number of teeth; therefore, people with large teeth in one part of the mouth tend to have large teeth elsewhere. ${ }^{2}$ Various previous studies have shown high correlation between mesio-distal size in left and right side of same arch. ${ }^{13,14}$

Moyer's prediction at $75 \%$ overestimated the mesio -distal size in maxillary arches of both males and female subjects. Previous studies done in Nepalese population present similar findings. ${ }^{8,9}$ In study done 
Table 4: Characteristics of the regression equation

\begin{tabular}{|c|c|c|c|c|c|c|}
\hline \multirow{2}{*}{$\sum \mathrm{CPM}$} & \multirow{2}{*}{ Sex } & \multirow{2}{*}{$\mathbf{r}$} & \multirow{2}{*}{$\mathbf{r}^{2}$} & \multicolumn{2}{|c|}{ Regression coefficient } & \multirow{2}{*}{$\begin{array}{l}\text { Standard } \\
\text { error of } \\
\text { Mean }\end{array}$} \\
\hline & & & & $\mathbf{a}$ & b & \\
\hline \multirow{3}{*}{ Maxillary } & M & 0.77 & 0.60 & 4.33 & 0.74 & 0.99 \\
\hline & $\mathrm{F}$ & 0.75 & 0.57 & 7.5 & 0.59 & 0.87 \\
\hline & $\mathrm{M}+\mathrm{F}$ & 0.75 & 0.57 & 6.4 & 0.64 & 0.92 \\
\hline \multirow{3}{*}{ Mandibular } & M & 0.79 & 0.62 & 2.7 & 0.80 & 1.0 \\
\hline & $\mathrm{F}$ & 0.75 & 0.56 & 6.5 & 0.62 & 0.92 \\
\hline & $\mathrm{M}+\mathrm{F}$ & 0.76 & 0.58 & 5.3 & 0.68 & 0.97 \\
\hline
\end{tabular}

$\sum$ CPM; combined mesio-distal width of canines and premolars, $r$; correlation coefficient, $\mathrm{r}^{2}$; coefficient of determination, $\mathrm{M}$; males; $\mathrm{F}$; females

Table5: Regression equation

$\begin{array}{lll}\text { SCPM } & \text { Sex } & \text { Equation } \\ \text { Maxillary } & \mathrm{M} & \mathrm{Y}=4.33+0.74 \mathrm{x} \\ & \mathrm{F} & \mathrm{Y}=7.5+0.59 \mathrm{x} \\ & \mathrm{M}+\mathrm{F} & \mathrm{Y}=6.4+0.64 \mathrm{x} \\ \text { Mandibular } & \mathrm{M} & \mathrm{Y}=2.7+0.80 \mathrm{x} \\ & \mathrm{F} & \mathrm{Y}=6.5+0.62 \mathrm{x} \\ \mathrm{M}+\mathrm{F} & \mathrm{Y}=5.3+0.68 \mathrm{x}\end{array}$

$\Sigma \mathrm{CPM}$; combined mesio-distal width of canines and premolars, M; males; F; females

Table 6: Tooth size prediction table based on regression equation developed by this study

\begin{tabular}{|c|c|c|c|c|}
\hline Sum of incisors & $\sum_{\text {maxillary }}$ CPM Male & $\sum_{\text {maxillary }}^{\sum \text { CPM Female }}$ & $\sum_{\text {Mandibular }}^{\sum \text { CPM Male }}$ & $\sum_{\text {Mandibular }}^{\sum C P M \text { female }}$ \\
\hline 18.5 & 18.6 & 18.4 & 17.5 & 18.0 \\
\hline 19 & 19.0 & 18.7 & 17.9 & 18.3 \\
\hline 19.5 & 19.3 & 19.0 & 18.3 & 18.6 \\
\hline 20 & 19.7 & 19.3 & 18.7 & 18.9 \\
\hline 20.5 & 20.1 & 19.6 & 19.1 & 19.2 \\
\hline 21 & 20.5 & 19.9 & 19.5 & 19.5 \\
\hline 21.5 & 20.9 & 20.2 & 19.9 & 19.8 \\
\hline 22 & 21.3 & 20.5 & 20.3 & 20.1 \\
\hline 22.5 & 21.7 & 20.8 & 20.7 & 20.5 \\
\hline 23 & 22.0 & 21.1 & 21.1 & 20.8 \\
\hline 23.5 & 22.4 & 21.4 & 21.5 & 21.1 \\
\hline 24 & 22.8 & 21.7 & 21.9 & 21.4 \\
\hline 24.5 & 23.2 & 22.0 & 22.3 & 21.7 \\
\hline 25 & 23.6 & 22.3 & 22.7 & 22.0 \\
\hline 25.5 & 24.0 & 22.5 & 23.1 & 22.3 \\
\hline
\end{tabular}


Table 7: Comparison of regression equation developed by various studies done in Nepalese subjects

\begin{tabular}{|c|c|c|c|c|c|c|}
\hline$\sum \mathrm{CPM}$ & Study By & $\mathbf{r}$ & $r^{2}$ & Regre & n coefficient & Standard \\
\hline Maxillary & Jaiswal et al ${ }^{9}$ & 0.51 & 0.26 & $\begin{array}{l}\mathbf{a} \\
13.35\end{array}$ & $\begin{array}{c}\mathbf{b} \\
0.35\end{array}$ & $\begin{array}{l}\text { error of mean } \\
0.88\end{array}$ \\
\hline & Gyawali et $\mathrm{al}^{8}$ & 0.71 & 0.51 & 6.3 & 0.66 & 0.91 \\
\hline & Present study & 0.75 & 0.57 & 6.4 & 0.64 & 0.92 \\
\hline Mandibular & 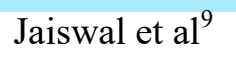 & 0.52 & 0.27 & 11.6 & 0.40 & 0.99 \\
\hline & ${\text { Gyawali et } \mathrm{al}^{8}}^{8}$ & 0.73 & 0.53 & 4.8 & 0.70 & 0.92 \\
\hline & Present study & 0.76 & 0.58 & 5.3 & 0.68 & 0.97 \\
\hline
\end{tabular}

$\mathrm{r}$; correlation coefficient, $\mathrm{r}^{2}$, coefficient of determination

by Gyawali et al, ${ }^{8}$ Moyer's prediction at $75 \%$ overestimated the mesio-distal size in maxilla and mandible in males; and mandible in females. Jaiswal et ${ }^{9}$ al didn't compare actual value with Moyer's prediction at $75 \%$ because they found that Moyer's prediction at $50 \%$ itself overestimated the mesio-distal size in Nepalese subjects. Moyer's analysis at $50 \%$ overestimated mesio-distal size in males but the difference was not significant statistically however in females statistically significant underestimation of mesio-distal size was seen when Moyer's prediction at $50 \%$ was used. Gyawai et $\mathrm{al}^{8}$ have reported that Moyer's 50\% underestimated the tooth size in both males and females while Jaiswal et $\mathrm{al}^{9}$ have reported the opposite. This may be due to difference in sample selection method. Gyawali et $\mathrm{al}^{8}$ have used only Bahun and Kshetri caste group samples where as in present study and study by Jaiswal et $\mathrm{al}^{9}$ have not used caste as exclusion criteria. Tanaka-Johnston analysis overestimate the mesio-distal size in both maxilla and mandible for males and females. This difference was statistically significant and similar to that reported by Gyawali et al, ${ }^{8}$ Jaiswal et al. ${ }^{9}$

Based on the sum of size of mandibular incisors and sum of canines and premolars, a regression equation was developed. The predictive accuracy of regression equation is indicated by coefficient of determination $\left(\mathrm{r}^{2}\right)$ values. ${ }^{9}$ In our study $\mathrm{r}^{2}$ values ranged from 0.57 to 0.62 indicating high accuracy of prediction equation. $\mathrm{r}^{2}$ values were higher for males as compared to females. The error involved in the use of prediction equations is indicated by the SEE the lower the SEE, the better the prediction equation. In our study the SEE values ranged from 0.8 to 1.0 . These values are similar to other studies conducted in Nepalese population (Table 7)

\section{CONCLUSION}

- Neither Moyer's probability chart nor Tanaka and Jhonston method accurately predicted the mesio-distal size of canines and premolars in Nepalese population.

- Regression equations developed by this method are accurate and can be used for mesio-distal size prediction in Nepalese population.

- Further studies with larger sample size are required to develop more precise regression equation.

\section{ACKNOWLEDGEMENTS:}

The authors would like to thank Mr. Dipendra Yadav, Dr. Vikram Shrestha, Dr.Kritka Shrestha and Dr. Sujika Tamang for their support during the study.

\section{REFERENCES}

1. Proffit WR, Fields HW Jr, Sarver DM. Contemporary Orthodontics, 4th Edn. St. Louis:Mosby, 2007, 195201.Chapter1:Malocclusion and dentofacial deformity in contemporary society; p. 3-24

2. Moyers RE. Handbook of Orthodontics, 4th Edn. Chicago:Yearbook Medical Publishers, 1988, p. 235-40.

3. Tanaka MM, Johnston LE. The prediction of the size of unerupted canines and premolars in a contemporary orthodontic population. J Am Dent Assoc. 1974; 88(4):798 -801. https://doi.org/10.14219/jada.archive.1974.0158

4. Proffit WR, Fields HW Jr, Sarver DM. Contemporary Orthodontics, 4th Edn. St. Louis:Mosby, 2007, 195201.Chapter 6:Orthodontic diagnosis: The development of a problem list; $\mathrm{p}$ 167-233

5. Bugaighis I, Karanth D, Elmouadeb H. Mixed dentition analysis in Libyan schoolchildren. J Orthod Sci. 2013;2 (4):115-9. https://doi.org/10.4103/2278-0203.123197. PMID: 24987652.

6. Sherpa J, Sah G, Rong Z, Wu L. Applicability of the Tanaka-Johnston and Moyers mixed dentition analyses in Northeast Han Chinese. J Orthod. 2015;42(2):95-102. https://doi.org/10.1179/1465313314Y.0000000122. PMID: 25588826. 
7. Alzubir AA, Abass S, Ali MA. Mixed dentition space analysis in a Sudanese population. J Orthod. 2016;43(1):33 -38. https://doi.org/10.1179/1465313315Y.0000000021. PMID: 26778242.

8. Gyawali R, Shrestha BK, Yadav R. Mixed dentition space analysis among Nepalese Brahmins/Chhetris. BMC Ora Health. 2016 Aug 2;17(1):36. https://doi.org/10.1186/ s12903-016-0265-1. PMID: 27484030.

9. Jaiswal AK, Paudel KR, Shrestha SL, Jaiswal S. Prediction of space available for unerupted permanent canine and premolars in a Nepalese population. J Orthod. 2009;36 (4):253-9. https://doi.org/10.1179/14653120723283 PMID: 19934243.

10. Chang HF, Shiau YY, Chen KC. The relationship of dental crowding to tooth size, dental arch width, and arch depth Proc Natl Sci Counc Repub China B. 1986 Oct;10(4):22935. PMID: 3562674

11. Poosti M, Jalali T. Tooth size and arch dimension in uncrowded versus crowded Class I malocclusions. J Contemp Dent Pract. 2007 Mar 1;8(3):45-52. PMID: 17351681

12. Howe RP, McNamara JA, Jr, O'Connor KA. An examination of dental crowding and its relationship to tooth size and arch dimension. Am J Orthod. 1983;83(5):363-73. https://doi.org/10.1016/0002-9416(83)90320-2.

13. Garn SM, Lewis AB, Kerewsky RS. The meaning of bilateral asymmetry in the permanent dentition. Angle Orthod. 1966;36(1):55-62. PMID: 5218762.

14. Bishara SE, Garcia AF, Jakobsen JR, Fahl JA. Mesiodistal crown dimensions in Mexico and the United States. Angle Orthod. 1986;56(4):315-23. PMID: 3466559. 